\section{VARIACIONES BIOPOLÍTICAS SOBRE NATURALEZA Y VIDA}

\author{
Luciano Espinosa Rubio \\ Universidad de Salamanca \\ espinosa@usal.es
}

Cómo citar este artículo/ Citation: Espinosa Rubio, L. (2013). "Variaciones biopolíticas sobre naturaleza y vida". Arbor, 189 (762): a054. doi: http://dx.doi.org/10.3989/ arbor.2013.762n4005

Recibido: 13 julio 2012. Aceptado: 6 junio 2013.

RESUMEN: Necesitamos nuevas narraciones para entender un poco más nuestro caótico y muy complejo mundo. En este caso es útil recordar algunos modelos históricos de las relaciones generales entre naturaleza y vida, que están en la base de la biopolítica: a) el tradicional, basado en la ley natural y en los valores de la vida; b) el técnico, basado en la voluntad de poder y en los valores de la libertad; c) el alternativo, basado en la cooperación ecológica entre todos los seres vivos y en ambas clases de valores. Para sobrevivir en esta crisis de civilización hace falta mucho coraje y solidaridad frente a la indiferencia que mata.

PALABRAS CLAVE: Biopolítica; Naturaleza; Vida; Autonomía; Solidaridad.

\section{BIOPOLITICAL ACCOUNTS OF NATURE AND LIFE}

Copyright: (C) 2013 CSIC. Este es un artículo de acceso abierto distribuido bajo los términos de la licencia Creative Commons Attribution-Non Commercial (by-nc) Spain 3.0.

ABSTRACT: We need new narratives to understand our chaotic and highly complex world a little better. In this case it is useful to remember some historical models of the general relations between nature and life, that underlie biopolitics: a) the traditional one, based on the natural law and life values; b) the technical one, based on the will of power and the values of liberty; c) the alternative one, based on the ecological cooperation between all living beings and both kinds of values. To survive in this crisis of civilisation, a lot of courage and solidarity is needed to confront the indifference that kills.

KEYWORDS: Biopolitics; Nature; Life; Autonomy; Solidarity. 


\section{PROPÓSITO Y CONTEXTO}

Vivir en una época de extraordinaria complejidad como la actual a menudo implica confusión, ya que no es fácil elaborar una explicación de conjunto que articule tantas relaciones y dimensiones como sería necesario. Sin embargo, es imprescindible vincular las diferentes lecturas del presente para entender mejor y actuar en consecuencia, pues tan perjudicial resulta el viejo metarrelato totalizador como el hoy omnipresente fragmento a la hora de lograrlo. Michael Ignatieff señala que hay dos grandes narraciones actuales, la globalización por un lado y la impresión de caos generalizado por otro, entendidos como fenómenos coherentes y contradictorios a la par, pero también genéricos e insuficientes. De ahí que sea preciso construir nuevos esquemas de comprensión, entre otras cosas para evitar la sensación de desbordamiento y la tendencia creciente a la "repugnancia moral" ante un mundo que parece enloquecido e ingobernable, dado que "el asco es un pobre sustituto del pensamiento" y que lo urgente es proporcionar "la base racional del compromiso ético" universalista a largo plazo, mediante la inteligencia de lo que sucede (Ignatieff, 2002, 40 y 137 s. $)^{1}$. Es obligado, pues, abordar el actual torbellino económico, ecológico, geopolítico, socio-cultural, biotecnológico, etc., desde múltiples perspectivas y recordar al menos algunas genealogías para mitigar la pérdida de referencias. En nuestro caso, ello supone aportar al pensamiento sobre las nuevas fronteras ontológicas y legales en los seres vivos el estudio de los nexos entre las nociones de naturaleza y vida, bajo los diferentes aspectos del poder y el deber, con la intención de contribuir a generar sentido en una época de oscuridad.

La cosmovisión de fondo troquela aspectos varios de la existencia, como es bien sabido desde los presocráticos, y en ese cruce de planos se dan cita intuiciones espirituales, intereses pragmáticos y proyectos sociales de todo tipo que conviene examinar. Por otra parte, el tema debe insertarse más que nunca en una suerte de vida global, dada la integración superlativa de ámbitos (ecológicos, técnicos y simbólicos) a escala planetaria que es propia del presente, lo que sin duda reclama una bioética y una biopolítica de gran alcance (Espinosa, 2007a). A su vez, este complejo multidimensional conlleva una ampliación de los campos de análisis: por ejemplo, a propósito de las conexiones de naturaleza y poder es adecuado tratar la gran revolución en marcha de las biotecnologías, pero también las circunstancias político-económicas de países no occidentales, en especial cuestiones tales como la soberanía alimentaria, la contaminación, los problemas asociados a los "agrocombustibles", la gestión pacífica de la grave escasez de agua o la "biopiratería" (es decir, el robo institucionalizado mediante "biopatentes" industriales), etc., pues en estos asuntos se ejerce un dominio creciente -directo e indirecto- sobre la vida que no desmerece de otros considerados canónicos.

Aquí no cabe ocuparse de todo ello, pero sí es posible delinear cierto tronco histórico e ideológico común, a través del contraste de tres modelos heurísticos que no son puros ni se suceden linealmente en el tiempo, sino que se mezclan y coexisten en grados diversos, lo que incluye el antagonismo y la complementariedad. A la hora de dar cuenta de las intrincadas relaciones entre lo llamado natural y lo cultural en torno a la vida, es útil seguir un hilo conductor: el paso progresivo desde la creencia en un gran designio inherente a la naturaleza (patente en los ciclos y/o fines cosmológicos, en la pertenencia de los seres a ciertos tipos invariables, la existencia de una moral y derecho naturales...) hacia un enfoque más constructivista y de diseño técnico, tanto en relación a lo humano como al medio ambiente. De hecho, algunos hablan ya del antropoceno para nombrar nada menos que una nueva era planetaria, supuestamente capaz de subsumir -por medios biotecnológicos- la vieja oposición de naturaleza y cultura en un proyecto unitario de renovado e imprevisible poder genesíaco.

Pues bien, a modo de esquema guía cabe mencionar un modelo tradicional (de corte religioso), otro tecnológico (secularizado y hoy dominante) y un tercero alternativo (apenas asentado), centrados respectivamente en la primacía de lo dado, de lo construido y de lo integrador. En forma paralela y correlativa, hay que referirse entonces a un cosmos cuasi sagrado del que se depende y en el que se confía en clave metafisica (con la consiguiente heteronomía práctica); a un mundo recreado por el artificio y sometido a imperativos humanos, desde cierta independencia al menos parcial (en un marco de autonomía); y a una patria planetaria a la que todos los seres pertenecen, con- 
cebida desde la auto-hetero-determinación ecosistémica (llámese internomía práctica). Cosmos, mundo y planeta son términos - usados sucesivamente- que ya denotan un tránsito evidente en el discurso. Sobre este trasfondo emergen las distintas concepciones de la vida humana, a menudo híbridas, pero tensadas alrededor de la perenne pugna entre libertad y necesidad, o, en su vertiente menos abstracta, emancipación y dominio. Es oportuno recordar, pues, algunos elementos básicos de las relaciones entre naturaleza, vida y poder, así como de los desplazamientos en el tiempo de sus respectivos límites y puntos de encuentro. Pero siempre desde el presupuesto básico de que todo ello es creación humana según la unión íntima entre ser e interpretación que Castoriadis ha llamado la "institución imaginaria de la sociedad": es el ejercicio permanente de la elección y del juicio a lo largo de la historia el que define el "mundo real" a través del "magma de las significaciones" (Castoriadis, 1998, 115 s., 181 s., 187) ${ }^{2}$. El caso es que para afrontar las grandes perplejidades y peligros del presente necesitamos nuevos significados y es obvio que no hay red de seguridad ni garantías de solución, por lo que conviene la humildad responsable del que asume la incertidumbre y la soledad metafísica. Lo que sigue es un pequeño equipaje conceptual de cara a esa urgente reflexión.

\section{EL MODELO TRADICIONAL}

Con evidente espíritu de síntesis, puede hablarse de una posición (mayoritaria en la historia del pensamiento) o conjunto de presupuestos fundamentales desde los que se parte: la naturaleza es entendida como fuente ontológica de verdad, valores y normas, en la medida en que obedece a un diseño providente, es decir, a una perfección superior de la que deriva todo sentido y legitimación ético-política. Hay en ello propósito, inteligencia y cuidado - no importa ahora si el modelo es trascendente o inmanente- que lo diferencia tanto del caos azaroso como del falible artificio humano, de manera que semejante plan intrínseco queda reflejado en la unidad y armonía del conjunto natural, y se enuncia en la metáfora del artesano que la habría modelado con sabiduría (Glacken, 1996, 49 y 648). Se trata de la disposición coherente y eficaz de las partes, de la regularidad de sus ciclos, de su belleza e idoneidad para la vida y, en fin, de todo cuanto asegura que las cosas son como deben ser. Al margen de las discrepancias sobre si esa impronta proviene o no de un creador personal, o sobre si prima la causalidad eficiente o la final, muy pocos han discutido la existencia de un orden totalizador y estable. El axioma de fondo que sustenta la cosmovisión es el isomorfismo entre physis-nomos-logos, o, si se prefiere en otro plano, la correspondencia y reciprocidad entre ser, pensar y decir, de la que derivan las construcciones culturales particulares. A partir de ahí, el mundo natural resulta inteligible, lo que proporciona seguridad y confianza, además de considerarse bueno y digno de imitación e incluso de obediencia. Esa especie de legalidad de vasto alcance cosmológico, epistémico, moral y jurídico queda bien resumida en los adagios clásicos que rezan "Natura agit rationaliter", "Natura semper est recta" o "Suprema decreta Dei, Natura", cuya contundencia habla por sí sola.

En segundo lugar, no puede extrañar que la concepción o imagen efectiva de lo real responda a motivaciones físico-teológicas (en la naturaleza hay pruebas de lo divino), por un lado, y a exigencias propias de una teología política que funda la organización social y el comportamiento (público y privado), por otro. Sea en el marco del holismo organicista y cíclico de la antigüedad o de la historia lineal y escatológica del cristianismo, lo que importa es atenerse a la Justicia cósmica que debe impregnar la vida humana en todas sus manifestaciones, cual vínculo entre lo macro y lo microscópico: por ejemplo, la "ley común" que menciona Heráclito atañe tanto al empeño intelectual como al plano político, pues ambos deben remitirse a lo divino que los origina (cf. frag. $114^{3}$ ), de modo que ese ajustamiento expresado a través de la proporción y la medida será el cimiento ontológico de los iusnaturalismos ulteriores. Es cierto que habrá en estos una clara evolución desde la idea de ley encarnada formal y materialmente en la naturaleza hacia la abstracción intelectual que solo aprecia una ley racional no empírica, pero permanece siempre un imperativo universalizador. Valga ahora una de las formulaciones sincréticas de esta matriz: "La verdadera ley es la recta razón, conforme a la naturaleza universal, constante y eterna (...) una sola ley eterna e inmutable que gobernará a todos los pueblos en todos los tiempos, y un solo Dios será el guía y señor de todos: él, precisamente, que ha concebido, redactado y promulgado esta ley" (Cicerón, De rep. III, 22, 33). Late por debajo una intención emancipadora en virtud de la igualdad atribuida a todos los hombres, pero también un papel legitimador de lo dado mediante la sanción expresa de las instituciones y códigos romanos que sirven de modelo dominante. Ambas cosas muestran el tránsito desde la mera visión metafísica hacia el control positivo de la vida, a través de la legislación correspondiente sobre contratos, relaciones de parentesco, propiedades, obligaciones de toda índole, gobierno 
de los placeres, etc. El resultado es que lo socialmente convenido se hace pasar por natural y lo adquirido por innato, toda vez que naturaleza, razón y ley parecen tener una misma raíz y van de la mano sin cuestionarse su origen ideológico. Con el añadido no menor de que lo habitual es poner todo ello al servicio del orden establecido, como bien ejemplifica el propio caso del estoicismo, donde prima la aceptación resignada y/o la huida desde los irreductibles antagonismos y conflictos mundanos hacia la armonía superior (Puente Ojea, 1979, 30-35, 110, 115, 233).

El cristianismo suscribe lo esencial de esta cosmovisión, aunque añade al Creador como vértice decisivo, claro está. Baste recordar que Tomás de Aquino solo entiende el mundo desde "la unidad de orden" (S. Th., I, 47, 3), con una estructura y jerarquía definidas en función del finalismo dictado por la providencia (S. Th. I, 22, 1), que no es otro que la orientación hacia el bien (S. Th., I, 93, 6). Luego la física vuelve a desembocar en la moral, una vez que en la naturaleza ya están unidas por medio de la ley natural que todo lo gobierna y a todos concierne. El hombre está llamado a captarla con su propia razón, justamente porque participa de ella (S. Th., I-II, 90, 4 y 91, 1 s.), de manera que la conexión entre lo universal y lo particular está ya impresa y asegurada en él. Lo interesante aquí es el papel que se reserva al apetito para dar el paso efectivo entre instancias, entendido como el resorte orgánico que moviliza a la razón aún antes que a la voluntad, y parece ser la infraestructura de ambas: es el apetito dirigido genéricamente al bien (S. Th. I, 6, 1 y De malo, 8,2 ), que después se desarrolla en diferentes planos y actividades, con lo que abre el campo de las tendencias, propensiones y deseos primordiales, de obvia importancia para definir la vida humana. En definitiva, la naturaleza (en conjunto y en cada individuo) es la plataforma básica desde la que se programan los derechos y los deberes, y por extensión las instituciones de toda índole, lo que desemboca en una suerte de recurrente control remoto sobre la historia, en cuanto que esta tiene por misión dar cumplimiento a los planes ínsitos en aquélla ${ }^{4}$.

De ahí que, en tercer lugar, sea obligado referirse a la intención práctica subyacente en todo lo anterior, donde el ser se desenvuelve como un querer y un deber que gira en torno a valores. El locus clásico de "vivir conforme a la naturaleza" lo resume bien, aunque a menudo quede la impresión de circularidad o de que no resulta explicado por completo en qué consiste. Dice Séneca, por ejemplo, que la naturaleza es guía y que la razón la "observa y consulta", lo cual conduce a la felicidad siempre que los sentidos sean mero lugar de paso y no haya servidumbre respecto a las cosas externas; esto es, desde otro registro, que solo hay virtud mediante la autarquía, incompatible con las zozobras de todo signo (Séneca, De vita beata, par. 8 y 15). Y es que se supone que la razón es nuestra genuina naturaleza, una vez desplegada la disposición que nos es propia (oikeiosis), pero cómo dar cauce adecuado a esta (lo previo) sin la racionalidad misma que nace de ella (lo derivado)... Además, hay otras paradojas, pues solo el esfuerzo y la constancia traen el éxito, pero igualmente hay que aceptar de buen grado lo que el destino depare. Por otro lado, es virtuoso quien actúa como conviene a cada caso -incluido en ello el importante cariz estético de la conducta-, pero justamente lo difícil es precisar la relación concreta entre naturaleza eterna, razón y variable circunstancia. Habrá que aceptar entonces que en eso estriba el arte (moral) de vivir... Algo que el sujeto precristiano - a pesar de sus temores y llamadas crecientes a la austeridad- puede realizar como cuidado de sí, no aplastado todavía por la omnipresente voluntad divina, la "caída" universal y la necesidad de purificación ascética (Foucault, 1978, vol. 2, 228 s.; vol. 3, 198, 218 s.). En cualquier caso, la naturaleza conserva en el paganismo mayor peso y concede mayor autonomía a la hora de construir la subjetividad.

La situación posterior viene definida por el hecho de que el cristianismo inicial convierte a su Dios en un soberano absoluto (Pantokratorikós), quien decide el destino del mundo en el contexto de la lucha apocalíptica del bien y del mal, estando este por vez primera interiorizado en los individuos en forma de pecado y rebelión (Meeks, 1994, 160 y 124, 129). La consecuencia inmediata es que lo natural, tanto en el plano cósmico como humano, queda postergado cuando no denigrado por corruptible, y que el antiguo ideal de convertirse en un hombre nuevo ahora solo es posible por la gracia divina. Sin embargo, junto a la sobrenaturaleza, ya consta que el tomismo rehabilitará los impulsos naturales porque afirma que los preceptos de la ley natural concuerdan con "el orden de las inclinaciones", lo que se expresa en los conocidos apetitos de conservación, procreación, conocimiento y vida en sociedad (S. Th. I-II, 94, 2). Estas variantes de la libido parecen limitar así tanto el voluntarismo como el intelectualismo moral, en tanto que actúan como condición de posibilidad del resto de facultades. Por otra parte, el vínculo entre cosmología y esta suerte de antropología traspasa la moral y llega al derecho y a la política, pues todas las leyes positivas derivan de la ley natural (S. Th. I-II, 95, 2), con lo que ese supuesto tiñe 
los asuntos pragmáticos más variados de la existencia. Una vez más, lo descriptivo deriva sin solución de continuidad en lo prescriptivo (expresión de la falacia naturalista y límite obvio a la libertad), dentro de un marco perfectamente clasificado y siempre opuesto a lo considerado antinatural, tanto en sentido ontológico como práctico.

La naturaleza, según el modelo tradicional, es vista como algo bien compartimentado y jerarquizado, donde cada individuo ocupa su lugar y cumple su función, ya se trate de la teoría del "lugar natural" de los cuerpos en Aristóteles (Fís. II, 199 b; III, 205 a) o de las tres clases de alma en Platón, con los rangos y deberes sociales correspondientes (Rep. 441 e- 442 a), por poner dos ejemplos célebres de transposición de lo cosmológico a lo físico y a lo social. La vida humana es definida entonces por nítidas fronteras ad intra y ad extra, lo que se traduce también en una diferencia de tipos naturales y en una noción del poder como dar de sí lo que uno es, a su vez desde el axioma de que lo inferior se subordina a lo superior en todos los ámbitos. De ahí la unidad de la legitimación cosmoonto-lógica y la simbólico-política de la autoridad, así como de las desigualdades de cualquier clase y de la dominación sobre la vida y la muerte de los sometidos, lo fueran por convicción o por fuerza. El ejemplo más claro del tamiz religioso que impregna la tradición occidental es la atribución de poder a la Iglesia católica como intérprete exclusiva de tales designios, algo que ella ha sabido ejercer de forma tan refinada como implacable en múltiples registros (Puente Ojea 1992, 3 s., 154 ss., 177 ss., 204). Lo que no solo es una vigorosa ilustración histórica de nuestro tema, sino un trasfondo vigente en las discusiones bio-ético-políticas actuales. Y es que el llamado orden natural de las cosas nunca ha desaparecido de la palestra como gran recurso, y resulta especialmente socorrido en épocas de cambio e incertidumbre como esta.

\section{EL MODELO TECNOLÓGICO}

3.1. Es conveniente empezar con algunos datos históricos y culturales que permitan bosquejar los elementos de continuidad, a la vez que de transición, entre los paradigmas. Así, la visión de un mundo estático perdura con el nacimiento de la ciencia moderna, cuyo mecanicismo cinético adolece de la misma visión atemporal y a veces de una peculiar referencia a la religión. Baste recordar la física del gran Newton, cuya teoría unificadora del cosmos parece compatible con la mención directa del "Señor del universo" y su voluntad soberana, siendo esta la única capaz de introducir variación en la ciega necesidad de la materia y bajo cuyo estricto dominio están todos los seres (Principia, Escolio general). Luego las leyes físicas son trasunto todavía - aunque formuladas bajo otros parámetros epistémicos - de las leyes divinas, y ambos tipos constituyen el patrón universal e inflexible del gobierno político de los individuos, los cuales están siempre sometidos a un orden superior y ajeno a ellos, lo que los impide toda iniciativa y vida espontánea: tal parece la correlación profunda entre lo físico, lo teológico y lo político, tanto en el plano de las fuerzas como en el de las leyes, es decir, en el paso solapado de la vis al imperium (Escohotado, 1999, 30, 116 s.). El modelo cosmológico se proyecta de nuevo - directa o indirectamente- en la vida humana, como cumplimiento de la voluntad divina que ha establecido una mecánica ordinaria del universo para todos los niveles y aspectos.

Aunque el creador se reserva la capacidad de intervenir y modificar en algo el orden necesario, bien para programar la materia o para salvaguardar la moralidad, lo que se impone poco a poco, sin embargo, es una suerte de automatismo de la naturaleza, más propio del deísmo secularizador que del teísmo. Por otro lado, esta rigidez de lo que se considera un orden lineal asoma igualmente en la biología, como atestigua el ejemplo notable de Linneo: su doctrina del fijismo supone afirmar una taxonomía intemporal, dado que la causa divina es inmutable y solo puede crear reinos y especies definitivos, sin cabida para las funciones o rasgos novedosos y mucho menos para los cambios sustanciales (Sist. de la Nat., Observaciones sobre los tres reinos de la naturaleza; Fundamenta botanica, V, afor.132). Visto en conjunto, el armazón de lo real permanece, de manera que el orden natural, el del conocimiento y el de la acción son correlativos en un mundo que se entiende dado de una vez para siempre, con su aparente salvaguarda de la inteligibilidad y de las instituciones de toda índole.

Como es sabido, las revoluciones políticas del XVIII$\mathrm{XIX}$, por un lado, y el evolucionismo darwiniano, por otro, alteran drásticamente ese cuadro inmóvil de la vida social y biológica, pero no debe olvidarse la previa labor de zapa de escépticos e ilustrados. El caso de Hume es muy revelador en términos filosóficos porque cuestiona de raíz el paralelismo entre el ordenamiento físico y moral del mundo, y vale la pena recordarlo: de entrada sostiene que desconocemos "la economía del universo" como un todo, y que esta bien puede provenir de la autoorganización de la materia, sin recurrir a planes externos a ella; y añade 
que deberían considerarse sin disimulos las muchas imperfecciones de lo real, especialmente la existencia del mal y de la infelicidad generalizada. En consecuencia, hay argumentos para pensar que la naturaleza es ciega e indiferente al bien y al mal, ante lo que solo cabe esforzarse con la industriosidad humana para paliar el dolor y satisfacer las necesidades de la mejor manera posible (Diálogos sobre religión natural, $\mathrm{X}$ y $\mathrm{XI})$. Se abre así paso el espíritu ilustrado que proclama la autonomía humana y la transformación de lo dado sin cortapisas religiosas, lo que a su vez creará el marco conceptual e ideológico adecuado para el avance de la técnica que el propio autor reclama. No es posible detallar esta vía racionalizadora, pero el hecho histórico es la evidente reciprocidad del desarrollo científico-técnico y del capitalismo, lo que define la edad contemporánea con sus tremendos éxitos y sus nuevas alienaciones.

Para ceñirnos a nuestro tema, hay que constatar que las supuestas leyes económicas que gobiernan la vida de la humanidad parecen solaparse con las leyes naturales que rigen el mundo, en la medida en que adquieren sus rasgos de universalidad y permanencia. La ideología del progreso es la quintaesencia en la que convergen todas ellas, en tanto expresión del curso inexorable de las cosas, de modo que el viejo naturalismo del aevum eterno deja su lugar al historicismo del tempus, pero aún se conserva la apelación a la necesidad común a ambos y también algunas pautas en el tránsito de lo descriptivo a lo normativo. Una de las variantes destacadas de esta alianza entre naturaleza, economía e historia es el darwinismo social, hoy redivivo, que sirve para legitimar una vez más la desigualdad (como en su día lo hizo con el colonialismo) en la medida en que distingue entre superiores e inferiores, ricos y pobres, etc., en razón de variables biológicas. Además, lo paradójico es que, junto al optimismo cientifista de las reformas y avances constantes, siempre ha coexistido un pesimismo antropológico muy conservador preocupado por dominar o al menos contener a la fiera humana, tanto en sentido político como orgánico. En ese contexto tiene cabida la utilización de supuestas medidas eugenésicas (tales como la esterilización), o profilácticas (como el encierro clínico), a menudo dictadas por "criterios de clase y de raza" en el seno de una ideología que pretende reducir hechos sociales a causas biológicas (Open University, 1983, 80 s.). Ese modelo socio-económico y médico que consagra el triunfo de los más fuertes (practicado en diverso grado por las democracias y llevado al extremo por los nazis) ha resultado tan eficaz y productivo como despiadado. No se pueden negar los cambios que en las últimas décadas han tenido lugar en las sociedades liberales, tales como la ampliación de la sanidad, la relativa redistribución de la riqueza o cierta movilidad social respecto a épocas pasadas, pero ello no deja de basarse en la explotación indiscriminada de la naturaleza y del hombre por el hombre, lo que opone límites estructurales a cualquier empresa radicalmente emancipadora. Lo significativo es que el biologismo retorna hoy con otros ropajes, pues la naturaleza ya no solo es -como antaño- fuente normativa y/o materia prima en la producción de riqueza (lo que supone una clara esquizofrenia a la hora de valorarla, por cierto), sino también el objeto de una definitiva remodelación, una vez que ha sido reducida técnicamente a la pura información que parece desmaterializarla y hacerla mucho más dúctil. El ápice del asunto es el acceso a las entrañas genéticas del ser, lo que convierte finalmente a la vida en categoría tecnológica (antes incluso que animal y social), susceptible de ser redefinida en su esencia y manejada a capricho.

Todo ello debe entenderse como el más reciente salto cualitativo en el proceso de apoderamiento de la vida surgido a partir del siglo XVIII, algo que ocurre - como ha enseñado Foucault - en términos orgánicos, sexuales, productivos, etc., a través de las variadas instituciones que normalizan y disciplinan a la población (fábricas, hospitales, escuelas, prisiones, cuarteles...), lo que hace preciso hablar de una "biohistoria" en la que insertar una "biopolítica" (Foucault, $1978,168-173)$. Sus efectos siguen vigentes y pueden sintetizarse en que la corporalidad es en cierto modo rehén del poder, pero hay que insistir en que este actúa no solo como represor, sino como generador de saberes y deseos que invaden y dirigen la subjetividad, en el marco de toda una "política de la verdad" y del sentido (Foucault, 1980, 106 s., 156, 179, 189). Tal es la tupida malla de prácticas y seducciones que amplían el alcance del "biopoder", hasta el punto de hacer que el enemigo esté ya en casa, por decirlo así, bien interiorizado. Sin embargo, estas aportaciones ya clásicas requieren algún complemento, al hilo del desarrollo histórico ulterior ya introducido que el filósofo francés hubiera sido el primero en atender. Junto a su enfoque de corte físico (mandan las fuerzas en juego), es preciso añadir una intensificación de la sutileza del poder a escala antes desconocida: sea en forma de un estilo de vida expandido y por completo ligado al consumo; en el hecho de traspasar el campo de la sexualidad hasta llegar a la manipulación genética y psicosomática en general; en la globalización de los procesos planetarios allende los estados; o, en otro plano, en la fulgurante reaparición de la santa alianza 
entre religión y política... Por otra parte, la normalización social adquiere hoy una difusa pátina estética y se instituye en un curioso proyecto universalista en virtud del cual todos los individuos se creen únicos y distintos, de modo que la desigualdad real de la que nace todo poder se traviste de libertad solo potencial y de juego de apariencias (simbólicas, de imagen, mediáticas, virtuales), en perfecto juego de camuflaje y engaño respecto a la limitada autonomía efectiva de los sujetos.

Esta red de la dominación obliga a ir mucho más allá de los antiguos poderes fácticos para entenderla, lo que supone incluir al mercado como institución central del entramado sociológico, la progresiva judicialización de la vida en muchos aspectos, el peso enorme de los medios de (des)información, de la publicidad o hasta de los fondos de inversión... Además del obvio economicismo que todo lo invade y de la marea especulativa que se ha provocado en su seno, es interesante reparar en el poder singular de "crear, difundir e imponer códigos de información" para influir en una sociedad saturada y llena de ruidos, en la que la resistencia política es cada vez más difícil ante la impersonalidad múltiple y global de las fuerzas rectoras (Estefanía, 2007, 192 y 70). La proliferación, metamorfosis e hibridación reciente de los poderes supone un bombardeo sobre los sujetos, envueltos en un haz de viejas y nuevas modalidades entremezcladas. De ahí que algunos invoquen otra vez el perenne "orden natural" para afrontar un devenir vertiginoso, en el que la vida humana está sometida a estímulos y requerimientos dispares y apremiantes que no sabe asimilar, por lo que a menudo aparece dislocada o inconsciente. Detrás de todo ello podría haber - según algunos autores - un cambio cualitativo, apreciable por ejemplo en el avance del llamado modelo digital en la sociedad del control (mucho más sofisticado que la analógica sociedad disciplinaria), conducido por una forma biotecnológica del poder que abarca todo el cuerpo social (Hardt y Negri, 2002, 39 y 43). Lo que sí debe concluirse es que la fusión plena de tecnología, economía y política permite dirigir mucho más a los sujetos, incluso suavizando los procedimientos, hasta colonizar la vida entera y fagocitar los brotes de disidencia como una variante más del consumo.

3.2. Para retomar el hilo conceptual de nuestro tema, habría que decir que ya no rige la posición naturalista, sino un artificialismo en el que no hay fronteras nítidas (entre la vida y la muerte, lo natural y lo artificial, lo orgánico y lo inorgánico, etc.), capaz de recombinar diversos planos y de diseñar otros aún inéditos. La nueva forma de la razón instrumental cuestiona las delimitaciones tradicionales del tipo que sean y se erige en la tecnología más potente nunca lograda: "La ingeniería genética es, quizá, el ‘agrandar el poder humano' sobre la vida por antonomasia" (Rifkin, 1998, 211). Jamás se había llegado a una capacidad de intervención y transformación - ¿̇no es eso el poder? - tan radical, con sus muchas ventajas y peligros, por eso el hecho básico que aún debe reglarse es la manipulación de los códigos últimos del ser vivo. La pregunta elemental pero obligada -en línea con los frankfurtianos - se refiere a si este es o no otro paso en la reducción de la existencia a cosa, es decir, a mero objeto de cálculo y de negocio sin cortapisas.

Por otro lado, semejante potencial demiúrgico, que hace saltar por los aires de manera definitiva la idea de una naturaleza acabada e independiente, replantea con vigor las relaciones entre seres, hechos y valores, dado que la distancia entre ellos se acorta y aparecen circunstancias y creaciones ontológicas desconocidas. En este marco constructivista, "El 'deber ser' se deduce del 'poder ser' (el imperativo tecnocrático). La vida se convierte en la 'principal categoría política' en cuanto objeto de destrucción, conservación, reproducción o incluso de producción" (Garrido Peña, 2004, 166). Desde programarla, tanto en sentido orgánico como conductual, hasta llegar a generar vida sintética, se abren expectativas ilimitadas que también alteran la vieja oposición entre libertad y necesidad: la acción biotecnológica crea espacios de autonomía antes impensables frente a lo necesario, pero igualmente puede impedir el comportamiento libre. En una palabra, el derrumbe creciente de las barreras ontológicas presenta desafíos inauditos y se corre el riesgo, a tenor de los precedentes históricos, de subordinarlo todo a una voluntad de poder sin freno, no menos temible y acaso más arbitraria que el viejo soberano de la naturaleza.

Respecto a la concepción genérica del mundo, en segundo lugar, parece claro que los medios técnicos mencionados refuerzan de modo superlativo el papel de la economía política: baste mencionar la gigantesca capacidad productiva y de diseño, o que la globalización se funda en el comercio y la especulación financiera (ajena a la generación de bienes y servicios, que solo representan el $5 \%$ del movimiento mundial de capitales). No extraña, en fin, que se hable de la mercadolatría o nueva "metafísica económica que absolutiza el mercado como panacea de todos los problemas" (Estefanía, 2007, 120), en cuyo ámbito hay que situar la vida cotidiana a todos los efectos, antes 
y después de la tremenda crisis actual. Las formas de poder mencionadas se condensan y articulan en torno a este núcleo mercantil, cuyo paradigma es el - provisionalmente denostado- neoliberalismo (privatización generalizada, desregulación total, recorte de la inversión pública, pérdida de derechos laborales, deslocalizaciones de empresas, etc.), de manera que el sujeto abandona y somete buena parte de su existencia a aquel ente casi hipostasiado, bajo la promesa de futuros beneficios para todos. Por no hablar del casino bursátil a escala planetaria, el gran autómata impersonal de las transacciones financieras electrónicas que se ha convertido en el nuevo dios ante el que nada se puede hacer, salvo pagar sus estropicios y abusos criminales. No es momento de insistir en la hipocresía fundamental del modelo (la libre competencia a menudo conduce al oligopolio, el Estado carga con las pérdidas y apenas puede ocuparse de la protección social, desigualdad creciente...), sino de apuntar que las llamadas fuerzas económicas se han convertido en la nueva naturaleza y definen el resto de variables hasta extremos desconocidos.

Así, las grandes multinacionales se han convertido en los agentes públicos de la vida colectiva por antonomasia (al menos en pie de igualdad con los estados), como indica el hecho de que algo más del $50 \%$ del PIB mundial está en manos de las 500 corporaciones más importantes. Añádanse a la globalización neoliberal las penúltimas convulsiones geoclimáticas, militares, terroristas, sanitarias, etc., o la creciente descomposición de las sociedades y la proliferación de los Ilamados señores de la guerra en muchos lugares, para comprender el surgimiento de ciertas organizaciones del poder. Por eso se habla de una vuelta al "sistema feudal", en el que los "cosmócratas" corporativos hacen un uso estructural de la violencia (en alianza con esos reyezuelos) para establecer una suerte de nueva "cosmogonía", no tanto ordenadora como explotadora (Ziegler, 2006, 17 y 44) ${ }^{5}$. Luego es obligado ampliar el enfoque biopolítico para incluir estos aspectos, dado que la vida de millones de personas depende en gran medida de esta combinación calculada y mortífera de elementos biológicos y financieros. Citemos al menos dos palancas respectivas de dominación, que bien merecen el nombre de "armas de destrucción masiva": el hambre que mata e incapacita en todos los órdenes a un número creciente de personas (más que las guerras) y la denominada deuda de los países pobres, en virtud de la cual envían más fondos al Norte de los que reciben como ayuda; con el resultado de que ambas cosas convierten en víctimas y en rehenes a gran parte de la población mundial (Ziegler,
2006, cap. VI y VII). Apreciar bien las consecuencias fisiológicas, sociales y políticas de todo ello requeriría un análisis muy extenso, pero es fácil calificarlas como implacables y tremendamente eficaces en términos de control de la vida.

Haya o no voluntad criminal expresa en tales o cuales actos económicos y geopolíticos de los poderosos, la evidencia es el abuso que arrasa con todo una vez que solo se busca el beneficio ilimitado a toda costa. En relación a la naturaleza, ya se apuntó el afán por privatizar recursos antes gratuitos como el agua, o la creación de patentes de seres vivos modificados (semillas, organismos...), en el marco de un proyecto de más vasto alcance: "Organizar la escasez de los servicios, de los capitales y de los bienes es la actividad prioritaria de los señores del imperio de la vergüenza (...) Hoy podemos decir que la miseria ha alcanzado un nivel más horroroso que en ninguna otra época de la historia. Así es como más de 10 millones de niños de menos de 5 años mueren cada año de desnutrición, epidemias, contaminación de las aguas e insalubridad" (Ziegler, 2006, 35). Ante una situación de crisis generalizada, la estrategia es controlar todo lo que es vital y producir los consiguientes efectos de dominación, de momento con mucha más crudeza en los países del Tercer Mundo. Por muy repartidas que estén las responsabilidades (incluidas, por supuesto, las corruptas élites locales), hay una conexión insoslayable entre la riqueza del Norte y la pobreza del Sur, así como en la expansión de los modos de vida de los primeros a costa de los segundos. La gestión biopolítica de instituciones, saberes y deseos que tanto ocupa a los bien alimentados teóricos occidentales debería apreciarse a esta luz, poniéndolo en relación con la mera supervivencia de aquellos desposeídos y analizando los instrumentos de poder específicos en cada caso, incluido el soborno masivo de las conciencias mediante un bienestar nacido en gran parte de la explotación.

Entonces tendrán cabida los problemas y alienaciones de los relativamente privilegiados, en la doble vertiente del llamado poder duro (nuevos medios de vigilancia y control, sin descartar la represión directa) y del más escurridizo poder blando sobre la vida. Es cierto que el primero se fortalece hoy en unas democracias devaluadas y adquiere tintes amenazantes, pero el segundo cala mucho más en la versión del consumismo como fenómeno omnímodo que resume y concentra otros aspectos:

"Los gestores cambiaron de la 'regulación normativa' a la 'seducción', de la vigilancia policial diaria a 
las relaciones públicas, y del imperturbable, excesivamente regulado y rutinario modelo panóptico del poder a la dominación por medio de la incertidumbre difusa y desenfocada, la precariedad y la caprichosa alteración de las rutinas. Y luego vino el desmantelamiento gradual del marco de servicios estatales en el que se solían desenvolver los aspectos primordiales de la política de la vida, así como el desplazamiento/deriva de dicha política de la vida hacia un terreno presidido por el mercado de consumo" (Bauman, 2006, 79 s.).

Esta coyuntura puede entenderse como un proceso multidimensional: se desmantelan servicios públicos básicos (crisis del Estado del Bienestar, erosión de derechos adquiridos, etc.), a la vez que aumentan e incluso se estimulan las ansiedades e incertidumbres de la población (precariedad laboral y económica, peligros globales, migraciones), con la consiguiente demanda de seguridad en detrimento de la libertad; mientras que son ofrecidos y aceptados hipotéticos consuelos o evasiones, lo que pasa indefectiblemente por las múltiples seducciones del mercado y a la postre desemboca en la privatización general de la vida.

Por eso el mayor problema no es el ejercicio tradicional del poder (modelo panóptico denunciado por Foucault), sino la interiorización complaciente o resignada de estas pautas, casi de modo subconsciente, y la compraventa de la autonomía personal que resulta de ello. Ahora la "política de la vida" se rige por un "síndrome consumista" (que incluye actitudes y juicios de valor, preferencias y modelos de felicidad, etc.) que impregnan el Lebenswelt en su conjunto, particularmente a través de la presunta satisfacción de necesidades que no dejan de aumentar (Bauman, 2006, 112,120 y 123). La red está echada y muchos dejan de ser ciudadanos para convertirse en simples consumidores, incapaces de practicar y reclamar en la esfera pública la solidaridad y el ejercicio de sus derechos. Nada más eficaz en este tipo de sojuzgamiento que apoderarse del cuerpo, como es bien sabido, pero no a la vieja usanza más o menos violenta, sino haciendo valer su condición siempre doliente o descontenta, llena de deseos, necesitada de cuidados y símbolos de estatus...

A todo ello responde bien -dando un paso más allá- el llamado capitalismo de ficción (posterior al de producción y al de consumo), cuyo objetivo no es tanto abastecer de productos cuanto proporcionar buenas sensaciones psicofísicas a los clientes, hasta llegar a crear nada menos que una "segunda realidad o realidad de ficción con la apariencia de una auténti- ca naturaleza mejorada, purificada, puerilizada"; y lo hace con tanta solvencia en la simulación que al final el capitalismo "se esfuma como artefacto de explotación para convertirse en mundo a secas" (Verdú, 2003, 10 s.). No se puede pedir más en la prestidigitación del poder: la masiva capacidad técnico-simbólica está en camino de convertir lo real en virtual y viceversa, donde nada parece lo que es ni es lo que parece, pero resulta manipulable casi a capricho. Además, el mundo se asemeja a un gran parque temático a disposición de quienes pagan y quieren divertirse, mientras que la degradación imparable de la naturaleza o la infantilización de la subjetividad solo son efectos colaterales. Sin embargo, la presente crisis económica y social (la vertiente funeral del capitalismo, según el propio Verdú, 2009) sirve al menos para anular ese enmascaramiento y mostrar la verdadera cara de las cosas por un tiempo. Lo que no se sabe es cuál será el grado de destrucción asumible y hasta dónde llegará la lucidez; o, dicho a la manera de Lampedusa, si se cambiará algo para que todo siga igual..

Corresponde hablar - por último- de la intención práctica que subyace en lo anterior, ya esbozada, pero que aún cabe matizar a través del examen de cierto tratamiento de los cuerpos y las almas. A modo de titular, podría enunciarse como la pérdida de la responsabilidad personal, bien sea en tanto que vuelta a la minoría de edad precrítica o como imposición al individuo de una determinada idea del bien común. Esta falta de autonomía se ejemplifica de forma paradigmática en el terreno de la salud: así, la actitud lúdica permitida al consumidor debe compatibilizarse, no obstante, con el nuevo mandato universal de llevar una vida sana, lo que a menudo tiene un ribete obsesivo y hasta puritano, no muy lejos por cierto del viejo ideal de disciplina y eficiencia. Lo curioso es que la ocultación de la muerte, el miedo excesivo a cualquier sufrimiento, la búsqueda ciega de la eterna juventud, la hipertrofia del deporte o una hipocondría más o menos difusa en la sociedad... son expresiones indirectas de un profundo malestar oculto en el mejor de los mundos posibles (hasta hace poco), a su vez ligadas al consumo creciente de productos y servicios sanitarios.

En términos específicamente biopolíticos es obligado citar la emergencia del Estado clínico, no solo guardián de la salud pública al modo tradicional, sino atento vigilante de su mejora material y simbólica en todos los órdenes. En él debe conjuntarse la tarea del buen gestor que racionaliza recursos y gastos con la del buen pastor que salva al sujeto de los desvaríos de 
sí mismo: "Se potencian los contenidos pastoriles con la legitimación instrumental de la gestión eficaz, y se amanceban lo utilitario y lo teológico, el rendimiento y la moralina. No hay noción más ideológica que esta y por tanto se presenta disfrazada de obviedad de sentido común" (Savater, 1990, 130). Hay que cuidarse por el bienestar físico, mental y económico de todos, podría resumirse, y si no se obedece se ejercerán las formas de presión correspondientes ${ }^{6}$. Ahora el interés por la salud orgánica (en este sentido amplio) sustituye a la antigua preocupación por la salud espiritual, pero conserva tonos imperativos semejantes, hereda en cierto modo el carácter de una ley natural (y del llamado sentido común) y cuenta con una burocracia sanitaria dispuesta a hacerla respetar. Sin olvidar, claro está, el sentimiento de culpa que a menudo estimula la autoridad -ahora por esta vía- como forma de autocensura. La libertad responsable de cada cual queda relegada en aras del nuevo bien absoluto, considerado superior e incluso ajeno a la decisión personal informada, bajo el supuesto de que los sujetos necesitan tutela de un tipo u otro y son incapaces de asumir las consecuencias de sus actos... Si uno no tiene derecho a decidir sobre su vida (aunque no dañe a terceros), menos aun podrá hacerlo respecto a su muerte, como prueba el empantanado y cínico debate sobre la eutanasia, por citar solo un ejemplo, donde los expertos y los autoproclamados defensores de la vida saben mejor lo que a ese uno le conviene.

Para completar el asunto debe mencionarse el renovado proyecto de crear un tipo de individuo más que sano, un auténtico súper o posthumano. Lo paradójico es que las nuevas biotecnologías así orientadas pretenden trascender el cuerpo mortal y falible para llegar a un tipo de sujeto inorgánico: el viejo ideal ético, religioso o político de transmutarse en el hombre nuevo se convierte ahora en el objetivo de crear el hombre biónico, potencialmente invulnerable al paso del tiempo y a la enfermedad. Se supone que este "procesará" su vida a partir de los datos genéticos y su posterior modificación, en el más puro estilo de la programación informática y robótica, lo que en términos colectivos de largo alcance abrirá una era que se ha llamado "postevolutiva" o "metadarwiniana". De modo que "la nueva tecnociencia parece ofrecer los elementos necesarios para realizar un sueño largamente añorado: modelar los propios cuerpos y almas, y así generar los más diversos resultados a gusto del consumidor (...) Una vez debilitadas las restricciones impuestas por la primitiva naturaleza, con sus severas leyes puestas en jaque, el sujeto contemporáneo se ve suavemente incitado a administrar su propio des- tino, tanto en el ámbito individual como en la escala de la especie" (Sibilia, 2005, 182). Es el triunfo del modelo fáustico de tecnociencia que traspasa fronteras ontológicas, frente al tradicional modelo prometeico que buscaba mejoras dentro de ciertos límites, es decir, un salto cualitativo a lomos del constructivismo ya referido y del afán eugenésico que lo legitima.

Los beneficios médicos están claros, otra cosa son los riesgos que se corren y las no pequeñas incertidumbres, amén de las diversas objeciones éticas ${ }^{7}$. La respuesta ilustrada al asunto no puede ser una vuelta a la supuesta e idealizada ley natural ni el rechazo de los evidentes progresos técnicos en la calidad de vida, pero sí hay que preguntarse si esa promesa implícita de mayor autonomía será cumplida por encima de otros intereses, incluidos los económicos y políticos. El caso es que hay motivos y antecedentes para dudarlo: por un lado, solo unos pocos podrán pagarse tales servicios, mientras que el negocio será fabuloso para algunos; y, por otro, los datos genéticos o los implantes biónicos también podrán usarse para manipular a las personas. Además, la noción misma de humanidad es cuestionada de raíz desde distintas posiciones por ser considerada tan imperfecta como díscola o peligrosa -intratable en definitiva-, y la respuesta que algunos dan es convertirla en un producto más para procurar su optimización psicofísica, una vez logrados los recursos biotecnológicos necesarios. Todo lo cual bien podría conducir, por ejemplo, a que haya seres humanos de primera, de segunda, etc., en función de las mejoras incorporadas. Así, la biopolítica del futuro está marcada por la posibilidad de crear menús ontológicos a la carta en todos los órdenes de la vida y con esa radical ambivalencia habrá que lidiar, aunque no sepamos bien cómo hacerlo.

En resumen, nos hallamos en un tiempo lleno de contradicciones que se plasman en diferentes registros del estilo de vida: globalizado pero rebosante de nacionalismos y particularismos, recreado por la tecnociencia que no acepta barreras pero apegado a esencias de corte étnico o racista, liberador del cuerpo en muchos aspectos a la vez que lo convierte en objeto e imagen (sexual, de estatus, publicitaria...). Por otra parte, la clásica tensión entre naturaleza y autonomía personal, entre valores de la vida y valores de la libertad, se resuelve aparentemente en un artificio que los integra tecnológicamente, pero a costa de negar tanto el universalismo naturalista de la tradición como el de corte histórico de la Modernidad, esto es, se suprime lo común en beneficio de la diferencia discrecional. Escasean los vínculos de unión y eclosio- 
nan los grupos, tipos e identidades diversas (sexuales, raciales, de intereses...), sumidos en una feroz competencia simbólica, económica y mediática. Crece no solo el justo reconocimiento de los oprimidos y un pluralismo tolerante, sino también la pugna entre derechos universales más abstractos y particularismos más corpóreos, por decirlo así, o entre una política de clases y otra biopolítica, etc. (Heller y Feher, 1995, 19, $26,44,88,109)$. A medio camino de un mundo que se va y de otro por llegar, los sujetos se enriquecen con distintas identidades y pertenencias, sí, pero también aparecen perplejos y fragmentados, atravesados por tantas relaciones de poder y de sentido que no es fácil orientarse ni promover la solidaridad.

\section{HACIA UN MODELO ALTERNATIVO}

Llegados a este punto no es fácil avanzar, ya que los proyectos alternativos están cuajados de problemas y resistencias. Resulta más fácil, como siempre, decir lo que no se quiere que concretar medios viables a corto plazo, especialmente ante el gravísimo calentamiento global. Lo único seguro es la necesidad de crear estructuras políticas y económicas más igualitarias y participativas para defender los Derechos Humanos, la capacidad para autodeterminarse de todos y la sostenibilidad ecológica. En otras palabras, la tarea de encauzar las perennes relaciones de poder a través de mecanismos cada vez más democráticos es tan ardua como imprescindible. Sirva aquí un breve apunte de algunas líneas de reflexión, que a la vez sea un balance de lo anterior por contraste.

De entrada, la más elemental enseñanza de la historia moderna afirma que la naturaleza no puede ser ya una instancia normativa, casi sagrada, ligada además a una razón apodíctica y monolítica que la conoce; pero la actual crisis de civilización también muestra que no debe ser reducida a mero objeto de explotación o de pura re-creación tecnológica, en función de los diversos estadios de la voluntad de poder y de su razón instrumental. Laicismo y autonomía personal, reflexión crítica sobre los límites teóricos y prácticos, sentido de la complejidad, conciencia ecológica efectiva, autocontención y responsabilidad... son algunos de los muchos elementos que respaldan este sencillo punto de partida y que ahora hay que dar por supuestos. La posición más coherente frente a esos dos polos recién rechazados (la esquizofrenia entre la subordinación y el dominio respecto a la naturaleza) es considerarla el hogar común y el soporte básico de la vida, aunque hasta ahora la sociedad no sea consecuente con un principio geobiológico tan claro en la versión profunda del término. Esta propuesta no es de un romanticismo trasnochado, sino la plena constatación de la interdependencia global, bien porque el gran ecosistema de sistemas muestra una autorregulación evolutiva que no puede ser perturbada impunemente, bien porque la cooperación (intra e interespecífica, cada una en su plano) es obligada en esa gran eco-organización, máxime ante hechos históricos de alcance planetario. Las razones y las emociones más clarividentes - que diversos pensadores y artistas han articulado- confluyen por tanto en una actitud respetuosa en términos morales, admirativa en sentido estético y conservacionista en clave pragmática. Eso significa, entre otras cosas, asumir la necesidad de un "copilotaje" entre ser humano y naturaleza, en el marco de "la comunidad de destino terrestre" (Morin, 1993, cap.9), pues la llamada sostenibilidad no es otra cosa que un acto de inteligencia y sensatez propio de quienes saben que viajan en la misma nave, y aúnan así la convicción y el interés.

Nada de eso significa confundir y amalgamar los distintos niveles del tema en la concepción derivada: es obvio que hay procesos naturales en los que rige un tiempo cíclico y prima la vida biológica, del mismo modo que hay proyectos humanos ineludiblemente antropocéntricos en los que rige un tiempo lineal y prima la conciencia. Los conflictos entre ambos planos son patentes y es absurdo hablar de armonía (noción complementaria de la de progreso, con pretensión ideológica semejante), pero lo que sí cabe es la convivencia, a pesar de las distinciones cualitativas de planos y de las difíciles elecciones que realizar. La vida humana resulta de la decantación de los dos aspectos, es decir, de su especificidad y de la unión con el resto, de la dependencia y la independencia respecto al medio natural, que siempre es también cultural. Por eso es preciso mantener y confiar en ciertos equilibrios ecosistémicos fundamentales y generar a la vez espacios propios de libertad, conscientes de vivir en un marco de amenazas terribles (cambio climático, contaminación y agotamiento de recursos, guerras...) e interconectadas, de modo que los cambios en las actitudes y conductas ecológicas, sociales y éticopolíticas se refuerzan mutuamente. La idea clara de pertenecer al planeta como un conjunto bio-cultural integrado favorece la mejor conciencia de todos los registros de nuestra humanidad, y viceversa. De ahí nace una visión del mundo alternativa y más compleja en los campos de la ciencia, la economía y la sociedad, que tiene consecuencias innovadoras de toda índole en la medida en que desencadena procesos sinérgicos en lugar de destructivos (Capra, 2003). Es preciso, 
pues, construir esos puentes de comunicación entre campos distintos y cuidar la vida en el planeta cuanto sea posible con unas perspectivas biopolíticas revolucionarias y convergentes.

La intención que deseamos destacar retoma la antigua idea de la concordia discordante, más allá de los antagonismos enquistados y de las lecturas pesimistas: se trata de pergeñar una visión ecológica (también ética y política) que coordine aquellas variables, con el empeño de someter los delirios tecnocráticos de toda laya a una visión humanista renovada. Eso implica luchar, claro está, contra la falsa ideología del crecimiento ilimitado en una biosfera finita y la cosificación de lo real (apoyada solo en términos cuantitativos en vez de cualitativos), que equipara sibilina o groseramente autonomía y consumo, mientras condena a la exclusión a la mayoría de habitantes de la Tierra y reduce la vida a una categoría biotecnológica susceptible de ser manufacturada. No cambiar esta situación resulta sencillamente criminal y suicida, cuando la prudencia es más necesaria que nunca con la puesta en marcha contemporánea de procesos impredecibles e incontrolados. A modo de síntesis, digamos que Jorge Riechmann ha identificado algunos de los conflictos esenciales (problema de escala en un mundo "lleno"; tecnosfera mal diseñada; derroche e ineficiencia generalizados; descontrol fáustico de la tecnociencia y creciente desigualdad) y ha propuesto ciertas vías (principios de precaución, de solidaridad sincrónica y diacrónica, de participación social y política, autocontención, biomímesis y ecoeficiencia) para lograr una "vida buena dentro de los límites" (Riechmann, 2006, 41 ss., 165-176). Perseguir algún tipo de simbiosis generalizada solo es posible desde la sobriedad de los deseos en una línea epicúrea, se dice, lo que propiciará una sabiduría del gozo y de la amistad. Algo verdaderamente imprescindible para enfrentarse una vez más - añadimos - al eterno enemigo de la vida que hoy se ha reforzado, el miedo.

En un mundo más agonístico que de costumbre si cabe, desgarrado por divisiones y amenazas de todo tipo, el miedo surge espontáneo, pero también se fomenta y se gestiona en la más pura tradición biopolítica del control, por lo que es condición previa afrontarlo y resistirlo mediante una maduración interna y un compromiso público (Espinosa, 2007b). En relación a nuestro tema, recordemos al menos tres grandes variantes del miedo: a la escasez (de agua y alimentos, de combustibles fósiles, etc.); a la inseguridad (peligros globales, terrorismo, epidemias...); y, en definitiva, a la ansiedad e incertidumbre generalizada y a no saber vivir adecuadamente (resolución de conflictos privados y públicos) en un entorno muy complejo y en ebullición. Junto a la frivolidad y la inconsciencia de una huida hacia delante, persiste el temor ante el aceleramiento de una historia que a veces parece desbocada. Estas son algunas de las caras recientes de eso que siempre se ha llamado el mal, ante cuya presencia la reacción más frecuente es desear ser salvados y protegidos..., aunque sea a cambio de obediencia y sumisión. Hoy se apela, por un lado, al optimismo de los poderes casi taumatúrgicos del mercado y de la tecnología, y, por otro, reaparecen viejas nociones teológico-políticas que aseguran la restauración del bien y del orden natural de las cosas, aun al precio pesimista de cierto apocalipsis como escarmiento purificador. En definitiva, hay motivos para temer nuevas variantes, no ya del populismo, sino del fascismo (con barniz tecnocrático) y del darwinismo social más cruento, cuando las cosas se pongan realmente difíciles.

De hecho, aprovechar los desastres de todo tipo -o provocarlos directamente- parece ser una de las estrategias favoritas del capitalismo salvaje para realizar cambios políticos y socio-económicos drásticos, aún más despiadados, cuando la gente no puede reaccionar por el estado de shock y el miedo que los embarga $(\text { Klein, 2007, } 30 \text { ss. })^{8}$. El ejemplo más cínico y actual es el intento de aprovechar la crisis económica para llevar a cabo reformas laborales y ajustes brutales a costa de quienes no la han provocado, pero sí la padecen. Junto a las consecuencias materiales para la mayoría de la población, en casos anteriores se han convalidado en sentido legal esas prácticas de latrocinio, así como el uso del terror para responder al terror, es decir, para ejercer la dominación y/o la defensa ante circunstancias especiales. No hace mucho, por ejemplo, hemos asistido al gravísimo retroceso que consiste en poner en cuestión y/o derogar los grandes logros biopolíticos de la Modernidad: el hábeas corpus y la prohibición de la tortura. Esa es la novedad de los guantánamos del mundo, de las medidas extraordinarias y de tanto estado de shock que podría llegar a convertirse en estado de sitio, real y simbólico. No son estos precisamente los modelos alternativos a seguir y acaso debamos ser más humildes a la par que radicales en las propuestas de cambio (Riechmann, 2009).

En términos conceptuales, hay que concluir que la antigua y tranquilizadora regularidad de la naturaleza deja paso definitivo a lo excepcional, que se convierte en paradójica norma de la historia e incluso de la misma naturaleza (cambio climático, catástrofes di- 
versas), cuya consecuencia biopolítica es el sobresalto continuo y su instrumentalización amenazante. Lo cierto es que la normalización institucional de la barbarie - legitimar el hecho con el derecho- sí que daría el triunfo a los fanáticos y desalmados de cualquier clase, por lo que nos vemos abocados a muy difíciles y necesarios debates sobre cómo limitar los daños y conseguir al menos... el mal menor (Ignatieff, 2005), no solo frente al terrorismo sino también ante los graves desequilibrios ecológicos. Remitirse al mal menor es síntoma y compendio de los tiempos (lúcidamente post-utópicos dirán unos, conformistas según otros), acorde con los riesgos y perplejidades que nos ase- dian, donde antes que nada parece obligado defender la supervivencia de la especie y los logros adquiridos de la libertad. Tal es la tarea biopolítica previa, la condición de posibilidad para luego seguir adelante hacia otras cotas de emancipación. Y es que, en último resumen, parece que este es el mundo al revés: lo natural se transmuta en artificial y la excepción se convierte en regla, tanto en clave biotecnológica como histórica y política. Por eso las fronteras de toda índole se difuminan para una vida humana que se siente tan llena de posibilidades como náufraga. En verdad hay mucho por pensar y por hacer, sin rendirse nunca, para revertir una situación harto difícil...

\section{NOTAS}

1 De la compasión temporal ante las crisis humanitarias es fácil pasar al desencanto por las repeticiones y los fracasos, e incluso a la misantropía, pero el hecho es que "la experiencia humana se enfrenta ahora a un abanico de nuevas situaciones - hambrunas de dimensiones continentales, catástrofes ecológicas, genocidios - que crean víctimas que carecen de relaciones para defenderse y que hacen que una ética de la obligación moral universal hacia los desconocidos sea necesaria para el porvenir del planeta" (Ignatieff, 2002, 34).

2 Ahí se constata, además, que lo habitua ha sido ocultar el carácter creador y contingente de la institución humana para buscar un fundamento necesario de origen religioso, lo que se cifra en la "ontología unitaria" según la cual e orden del mundo y el de los asuntos humanos es común. Por el contrario, el estrecho lazo genealógico entre filosofía y política democrática legado por Atenas muestra que no hay tal y que debe optarse libremente en un camino sin fin, según el autor.

3 Procuro utilizar referencias básicas y concisas de las fuentes, al margen de las ediciones particulares, e incluirlas en el texto para facilitar el seguimiento.

$4 \mathrm{El}$ asunto se formula de modo diferente según las épocas, pero presenta constantes. Sirva el ejemplo paradigmático del prudente Kant, quien afirma que "Se puede considerar la historia de la especie humana en su conjunto como la ejecución de un plan oculto de la naturaleza para (...) desarrollar plenamente todas sus disposiciones en la humanidad", lo que remite finalmente a la providencia (Kant, Idea para una historia universal..., parágrafo 9).

5 Obviamente no es solo un juicio ideológico, sino que surge del contraste de datos y argumentos que Ziegler conoce de primera mano como antiguo relator de la ONU para la alimentación.

6 Como botón de muestra, vale recordar la decisión del Gobierno británico de colocar a los fumadores en la cola de las listas de espera sanitarias, como si ellos no pagaran impuestos directos e indirectos...

7 Me he ocupado del tema con amplitud en "El desafío del posthumanismo. En relación a las nuevas tecnologías", dentro del colectivo Humanismo. Teoría cultural de Europa, coordinado por Pedro Aullón y en vías de publicación.

8 El repaso de la historia más reciente (con múltiples ejemplos concretos) que realiza la autora en la obra es tan revelador como documentado, y deja pocas dudas sobre la miseria moral y política del economicismo depredador. La presente debacle financiera y económica parece haberle dado más que la razón.

\section{BIBLIOGRAFÍA}

Bauman, Z. (2006). Vida líquida. Barcelona: Paidós.

Capra, F. (2003). Las conexiones ocultas. Implicaciones sociales, medioambientales, económicas y biológicas de una nueva visión del mundo. Barcelona: Anagrama.

Castoriadis, C. (1998). Los dominios del hombre. Barcelona: Gedisa.

Cicerón: Sobre la República.
Escohotado, A. (1999). Caos y orden. Madrid: Espasa.

Espinosa Rubio, L. (2007a). “La vida global (en la eco-bio-tecno-noos-fera)". Logos. Anales del Seminario de Metafísica, vol. 40, 55-75.

Espinosa Rubio, L. (2007b). “Contra el miedo. Spinoza y Fromm". Thémata 38, 47-60.

Estefanía, J. (2007). La mano invisible. El gobierno del mundo. Madrid: Punto de Lectura. 
Glacken, C. J. (1996). Huellas en la playa de Rodas. Naturaleza y cultura en el pensamiento occidental desde la Antigüedad hasta finales del siglo XVIII. Barcelona: Ed. Serbal.

Hardt, M y Negri, T. (2002). Imperio. Barcelona: Paidós.

Heller, A. y Feher, F. (1995). Biopolítica. La Modernidad y la liberación del cuerpo. Barcelona: Península.

Hume: Diálogos sobre religión natural.

Ignatieff, M. (2002). El honor del guerrero. Madrid: Punto de Lectura.

Ignatieff, M. (2005). El mal menor. Ética política en una era de terror. Madrid: Taurus.

Jünger, E. (1988). La emboscadura. Barcelona: Tusquets.

Kant: Idea para una historia universal en clave cosmopolita.
Klein, N. (2007). La doctrina del shock. El auge del capitalismo del desastre. Barcelona: Paidós.

Linneo: Sistema de la naturaleza y Fundamentos de botánica.

Meeks, W. A. (1994). Los orígenes de la moralidad cristiana. Barcelona: Ariel.

Morin, E. (1993). Tierra Patria. Barcelona: Kairós.

Open University (1983). Historia y relaciones sociales de la genética. Barcelona.

Puente Ojea, G. (1992). Fe cristiana, iglesia, poder. Madrid: Siglo XXI.

Puente Ojea, G. (1979). Ideología e historia. El fenómeno estoico en la sociedad antigua. Madrid: Siglo XXI.

Riechmann, J. (2006). Biomímesis. Ensayos sobre imitación de la naturaleza, ecosocialismo y autocontención. Madrid: Los libros de la Catarata.
Riechmann, J. (2009). La habitación de Pascal. Madrid: Libros de la Catarata.

Rifkin, J. (1998). El siglo de la biotecnología. Barcelona: Crítica.

Savater, F. (1990). Humanismo impenitente. Barcelona: Anagrama.

Sibilia, P. (2005). El hombre postorgánico. Cuerpo, subjetividad y tecnologías digitales. Buenos Aires: FCE.

Tomás de Aquino: Suma teológica.

Verdú, V. (2003). El estilo del mundo. Barcelona: Anagrama.

Verdú, V. (2009). El capitalismo funeral. Barcelona: Anagrama.

Ziegler, J. (2006). El imperio de la vergüen$z a$. Madrid: Taurus. 